\title{
Psychiatry and the death penalty
}

\author{
Marianne Kastrup Frederiksberg Hospital, Denmark
}

\section{Author's abstract}

Mentally ill people are not to be judged by the same rules as
the mentally fit. Prisoners evaluated medically unfit for
execution must undergo psychiatric treatment until their
mental health is restored. Psychiatrists are placed in an
ethical dilemma when asked to judge the mental health of
prisoners on death row. A high prevalence of psychiatric
and neurological disorders are reported on death row.
Health professionals have an important role in
implementing codes of ethics prohibiting any involvement
in the execution process. Resolutions have already been
passed by several associations including the World Medical
Association, the American Psychiatric Association and
Nordic medical associations.

The issue of capital punishment has produced considerable controversy in society with regard to both its effectiveness as a deterrent and the ethics of its use (1). Society's fear of crime and the mass-media emphasis on violent crime encourage the public to view violent crimes as more of a problem than they actually are. Over the years a number of arguments have been put forward in the public debate pro et contra the death penalty including that: the death penalty is a deterrent because a person tempted to commit a capital offence will desist to avoid the possibility of execution; the death penalty provides justice by meeting society's need to revenge itself for its loss; serious offenders deserve to die because they have committed acts which have put them outside the rights of the human race (1).

The arguments used against the death penalty often focus upon the view that it contravenes the right to life as stated in human rights declarations. Also, it is argued, the death penalty is immoral and violates the modern teaching of most major religions; the death penalty is cruel, inhuman and degrading; it is unfair as it almost always will fall on minorities; the death penalty is irrevocable; it is obstructive of attempts to apply modern criminology, and it condones violence as a means of coping with society's problems.

Furthermore, the death penalty has no preventive effect and it risks providing a false sense of protection

\section{Key words}

Capital punishment; death row; psychiatric ethics. and is wasteful, not only of human life, but also because of the cost of the endless legal machinery it $\vec{A}$ requires (1).

\section{Resistance to abolition}

It may be difficult for many people to come to a rationalo decision on the death penalty as the primary resistance to the abolition of the death penalty is not rational but is connected to strong emotional feelings, conscious or unconscious. One such feeling may be that of the need ${ }_{3}^{\mathbb{\Phi}}$ for a 'scapegoat': that the person whose misdeed iso discovered and who is punished by death serves to expiate the guilt engendered by the crimes of all.

Alternately, society may use the death penalty $\mathfrak{g}_{0}^{\infty} 00$ focus upon the condemned as the embodiment $\rightarrow$ fi human sinfulness (the 'sacrificed lamb') and, at same time, magically to insinuate the survivors into the grace of God by the sacrifice.

Finally, reference can be made to the need felt by individuals to develop defences against their own secret destructive impulses. The average person senses? his basic instinctual relationship to the violent criminal and may become anxious that if the death penalty is eliminated he/she will be forced to rely more on his/her own internal control and less upon fear of punishment (2).

\section{The participation of health professionals}

There is nothing new about the medical profession's participation in executions. Doctors and other professionals have been present at, and have had rolesin, official executions for centuries. As an example, the guillotine was invented by a physician who opposed the death penalty and thought the guillotine a mores humane method of killing. Further, a commission of American doctors opposed execution by hanging in 1887 because it frequently prolonged suffering, and recommended more humane forms of killing, favouring electrocution (3).

The death penalty is still an issue for medica觓 professionals. Physicians and other medical personne $\Gamma^{+}$ are reported to take part in the execution process by examining prisoners prior to execution, by staying in the death chamber, and by monitoring the prisoners $\stackrel{?}{\mathbb{P}}$ condition either during electrocution or letha injections and advising whether or not to continue the execution. Often they have been charged with 
functions such as examining the prisoner (4) or placing a mark on the chest of the prisoner before shooting (5). In several countries, execution cannot take place without the participation of doctors even when the traditional methods are used. A minimum requirement is that the doctor certifies death.

There have, however, been several examples of very active participation of doctors. In one case in the USA, a physician and a medical assistant helped to strap the prisoner to the electric chair, and the struggle was reported to last for seven minutes. In another case a physician monitored the prisoner's heartbeat, indicating that the execution should continue for a few more minutes (6).

To summarise, doctors may be called on to participate in executions by, among other things, determining fitness for execution, giving technical advice, prescribing, preparing, and administering or supervising the injection of poison and making medical examinations during the execution in order to advise continuation of the execution if the prisoner is not yet dead (1).

\section{Dilemmas}

These problems, amongst others, imply that a physician may easily find himself in an ethical dilemma. One problem is the so-called 'fit-forexecution' certificate. Treating prisoners on death row may result in grotesque situations where an execution cannot take place because the prisoner has fallen ill and the doctor's task is to restore him or her to a condition which allows execution. In this way the physician may easily find himself in a key position where his evaluation is the decisive factor determining whether the prisoner is executed or not and he may be required to use professional skills for the sole purpose of restoring the prisoner to a condition which makes him fit for execution.

Finally it needs emphasis that the presence of a physician can be used to lend credibility to the act of execution and deflect the responsibility from those who have ordered the execution.

\section{The participation of psychiatrists}

One basic principle of forensic psychiatry is that it is morally unjust to evaluate and judge mentally ill persons by the same legal rules as people who are mentally fit, punishing them for acts which are a consequence of their disorder.

The function of the psychiatrist is that of providing the court with a medical answer to whether any significant psychiatric disease or mental deficiency is present. The verdict 'guilty but insane', that is not responsible, is a legal task and has yielded protection against the imposition of a death sentence (7).

From a legal point of view (8) two areas of concern are raised by psychiatric participation.

The first concerns the examination of the defendant without making reasonable efforts to assure that he has full understanding of the significance of this examination, that is the examiner's opinion as to his dangerousness. Traditionally, this problem has been approached by asking whether the subject has any right to refuse co-operation. From an ethical point of view it is offensive to encourage a criminal defendant, especially one who is unaware of the true nature of the situation, to participate in an interview the end result of which may be to cause him to be put to death. It may thus be concluded that no prosecution psychiatric testimony should be admitted on the death penalty issue if that testimony is based upon an interview with the defendant unless it is shown that prior to the interview the defendant recognised his privilege against self-incrimination.

The second area of concern is the inadequate crossexamination of psychiatric testimony presented in capital trials. Lawyers provided for defendants by the court may fail to cross-examine witnesses or present contrary testimony by other psychiatrists.

Furthermore one should be concerned with the quality of the psychiatric examinations and testimonies. Of major concern here is whether psychiatrists are particularly qualified to give opinions on future dangerousness.

\section{Future dangerousness}

In some states with death penalty statutes (for example Texas) one factor which leads to the imposition of the death penalty on the convicted prisoner is the probability that he or she will commit similar acts of violence in the future. To determine likely future dangerousness, evidence from psychiatrists may be intoduced and this testimony has been an influential and, in some cases the key, factor in convincing the jury to vote for the death penalty (6).

The role and capacity of psychiatrists in assessing future dangerous acts has been examined in detail in a number of cases. An important example was the case of Barefoot versus Estelle. At his trial two psychiatrists testified that someone of Barefoot's character would probably commit further acts of violence and that therefore he represented a continuing threat to society. This evidence led to Barefoot being sentenced to death. He subsequently appealed, claiming that the use of psychiatric testimony was unconstitutional because a psychiatrist had no special competence to make evaluations of future dangerousness. The American Psychiatric Association (APA) also rejected the use of psychiatric testimony based on hypothetical questions, asserting that research indicates that even under the best of conditions psychiatric predictions of long-term future dangerousness are wrong in at least two out of every three cases. They concluded that in the Barefoot case, a psychiatrist was allowed to masquerade personal preferences as 'medical' views (9). On the other hand, it should be recognised that there is little evidence that those other than psychiatrists are good at predicting dangerousness either.

Furthermore, recent research indicates that the most reliable predictor of future violent behaviour are factors that have nothing to do with mental illness such as age, sex and past dangerous behaviour and that the 
forecast of future dangerousness is primarily not an expert psychiatric one (8). The US Supreme Court has made the observations that "neither the prisoner nor the American Psychiatric Association suggests that psychiatrists are always wrong with respect to future dangerousness, only most of the time' (9).

Psychiatrists have given a number of rationales for their participation in this process including that more conservative and prosecution-prone colleagues would then take over. This is, however, like saying good people should do bad things because otherwise only bad people will do bad things.

\section{Assessment of competence}

It is accepted practice in many states that insane prisoners should not be executed. Psychiatrists take an active part in evaluating a defendant's competence to stand trial and in assessing the convicted person's capacity for psychiatric rehabilitation. Generally no ethical problem is seen with such activities.

Another more difficult issue is the psychiatric assessment of the mental condition of the prisoner to be executed. This procedure to determine competence varies in the USA from a full court hearing to an evaluation according to the assessment of the prison warden. A dilemma exists for psychiatrists as to what extent they should participate in determining competence (8). Some psychiatrists may argue that an assessment of competence to be executed does not differ from other tasks psychiatrists are called upon to perform. Another position recognises profound differences between this evaluation and other evaluations since the assessment has life-and-death implications for the subject. Psychiatrists who support this approach emphasise that the standards used for determining competence should be clarified and that the prisoner should be allowed to call his own expert. Finally, some psychiatrists reject the idea of participating in evaluations of competence of prisoners condemned to be executed. They stress that the only purpose of such an evaluation is to facilitate the administration of punishment, which is a role that psychiatrists should avoid.

In the US, the Supreme Court ruled in 1985 that states must provide free psychiatric assistance in preparing an insanity claim and, in 1986, that it is unconstitutional to execute a prisoner who becomes insane while awaiting execution (6).

Here a possibility may arise that psychiatrists become doctors at risk. It has been suggested that the court in which the prisoner is presenting evidence concerning his sanity need not be presided over by a judge. This would mean that psychiatrists perform an evaluation and also present evidence, thus acting as the ultimate decision-makers as to whether the prisoner is to be executed. Regardless of whether the right is constitutionally based or not, determination of competence to be executed presents a difficult problem for mental health professionals.

\section{Treatment of the incompetent}

It is, as mentioned, in many states required that prisoners be competent before the execution...? Psychiatrists may therefore find themselves in $a \overrightarrow{=}$ dilemma when a prisoner is found incompetent - either at the time of the trial or as a consequence thereof. Should the psychiatrist accept the task and treat the prisoner, well aware that a successful treatment may result in the person's execution (8)? No easy answer can be given. Some clinicians believe that theires responsibility as psychiatrists is to treat mental illness $\vec{\circ}$ whenever possible, without regard to the prisoner'sstatus as a condemned prisoner. Others reject the ideaw that they should be asked to restore a prisoner to a mental state which would allow an execution to proceed. For them the relief of suffering in the short $-\vec{A}$ term must be weighed against the long-term interest of the prisoner. Psychiatrists who favour this position might argue that it is more humane to let a persone suffer from a psychosis than to treat the psychosis, thereby threatening the life of the prisoner. Finally some favour an intermediate position; they are willing to treat those prisoners who themselves want to be treated (8).

Different ways exist out of the dilemma. One® possibility might be automatically to commute a death $-\overrightarrow{0}$ sentence to life imprisonment in cases where a prisor 80 is shown to be incompetent. Another possibility migit: be to abolish the requirement that prisoners must $\vec{b} e_{0}$ competent when executed (though, in the US, tris would contravene the US Supreme Court's ruling ono the constitutionality of executing insane prisoners).

\section{Psychiatric problems of death row}

Two kinds of psychiatric problems are to be found on death row: 1) problems that are present in prisoners on death row, and 2) problems that are caused by the conditions on death row.

1) An important issue is psychiatric disorders suffered by condemned prisoners. In a recent surveyo(10) the neuropsychiatric characteristics of 15 men and. women who were sentenced to death in the US between 1976 and 1984 were presented. The study represents the first systematic clinical investigation of individualso waiting to be executed and the subjects were selected not because of any evident psychopathology bu because of the imminence of their executions.

All were psychiatrically evaluated and detailed? neurological histories were obtained. All 15 had histories of head injuries. Five subjects had majotw neurological impairments such as paralysis or corticab atrophy and a further seven had histories of black-out and psychomotor epileptic symptoms. All but one of the eleven subjects psychologically tested were of? normal intelligence.

As regards the psychiatric symptoms, nine of the $150^{\circ}$ subjects suffered psychiatric symptoms during childhood of a nature so severe that they had neededि consultation. Six subjects were found to be chronicallyo psychotic, and their psychotic history antedated their 
imprisonment. Three more subjects were episodically psychotic, and two subjects suffered from symptoms consistent with DSM-III criteria for bipolar mood disorder (manic-depressive).

It may of course be questioned whether these prisoners indeed were representative of death row prisoners. The authors imply that a majority of death row prisoners have long-standing neurological or psychiatric disorders, many of them associated with traumata in early life and that they would have had much to gain by convincing the examiners they were impaired. The question is: Why were these serious disorders not identified during the trials? One answer suggested by the authors is that nobody suspected them and thus nobody looked for them. The fact that the disorders were not previously identified conflicts with the view that murderers are sociopaths who will feign any illness to escape their punishment. The possibility remains that these prisoners constitute a severely impaired population of prisoners who are less able to get competent attorneys to defend their cases, though undoubtedly socio-economic factors play an important role here.

2) The anticipation of death at a specific time is an extremely stressful factor that has been studied in a survey of inmate response to death row confinement (11). A number of psychological symptoms can be observed in death row inmates: both clinical evaluations and psychological testings demonstrate a 'hardening' of psychological defences over time. Some condemned prisoners went on manifesting marked symptomatic responses in relation to stress, but more described a lowering of perceived stress. The findings suggest that it is possible to adapt to some extent to the death row experience, but the adjustment may result in a socially undesirable position.

\section{How to change the situation}

Is it morally justifiable that psychiatrists participate in trials in which their testimony may be decisive for the life or death of another human being? Is it morally justifiable that psychiatrists should decide who is fit for execution, or that psychiatrists treat the psychotic person with the consequence that he/she gets so well that he/she is found fit for execution? Can we as psychiatrists accept this situation? And if not, how do we change it? It is my hope that psychiatrists and other medical professionals worldwide will condemn medical participation in capital punishment unconditionally.

At the World Medical Association's assembly in Lisbon in 1981, a resolution was passed including the passage 'it is unethical for physicians to participate in capital punishment although this does not preclude physicians certifying death'. The United Nations' principles of Medical Ethics specifically preclude the participation of physicians in any cruel, inhuman or degrading treatment or punishment.

The medical associations of 17 countries have indicated their support of the World Medical Association resolution opposing involvement of doctors in the death penalty. In June 1986 a resolution was passed by representatives of all Nordic medical associations, declaring it indefensible for any physician to participate in any act connected to and necessary for the administration of capital punishment. The American Psychiatric Association has resolved that the physician serving the state as executioner is a perversion of medical ethics and the association strongly opposes any participation by psychiatrists in capital punishment. In the annotated Principles of Medical Ethics (12) it is mentioned that a psychiatrist who regularly practises outside his/her area of professional competence should be considered unethical.

Determination of professional competence should be made by peer review boards or other appropriate bodies. Such and other similar principles for ethical conduct could be a safeguard against psychiatrists overlooking disorders or giving inappropriate evidence in court.

If a complaint of unethical conduct is sustained the psychiatry member should receive a sanction. These sanctions could take many forms, from admonishment to expulsion from a professional organisation, and the intensified debate thus sparked off might lead to an increased awareness of the ethical dilemmas.

'Doctors at risk', which comprises those who work for authorities and who risk committing human rights violations, may be under considerable stress if refusing to co-operate, and the establishment of a professional network to provide support is essential.

This could be helpful for psychiatrists who in court are ordered to reveal confidences of patients and who reserve the right to raise the question of need for disclosure; or in cases where psychiatrists feel that their testimony is being used by the legal profession outside the context for which it was meant.

This is encouraging but more needs to be done. Professional associations have much to contribute to the defence of human rights and to the objective of removing doctors from the execution chambers and associated legal processes.

Marianne Kastrup is a specialist in psychiatry. Her present position is Chief Consultant in the psychiatric department of a teaching hospital in Copenhagen. She is active in the Medical Group of Amnesty International and the Medical Group against the Death Penalty.

\section{References}

(1) Amnesty International, Canadian Section Medical Network. Health care and human rights. Toronto: 1987, 5,1 .

(2) West L J. Psychiatric reflections on the death penalty. American journal of orthopsychiatry. 1975; 45: 689-700.

(3) Curran W J, Casscells W. The ethics of medical participation in capital punishment by intravenous drug injection. New England journal of medicine 1980; 302: 226-230.

(4) Hussain A H, Tozman S. Psychiatry on death row. Fournal of clinical psychiatry 1978; 39: 183-188. 
(5) Dix G E. Psychiatric testimony in death penalty litigation. Bulletin of the American Academy of Psychiatry Law 1977; 5: 287-293.

(6) Amnesty International. The death penalty in the United States of America: an issue for health professionals. London: Amnesty International, 1987.

(7) Reich W. Psychiatric diagnosis as an ethical problem. In: Bloch S, Chodoff P, eds. Psychiatric ethics. Oxford: Oxford University Press, 1981.

(8) Appelbaum P S. Competence to be executed: another conundrum for mental health professionals. Hospital and community psychiatry 1986; 37: 682-684.
(9) Brief for Amicus Curiae, American Psychiatric Association. Supreme Court of the United States, OcE्ञ term 1982. Barefoot $v$ Estelle.

(10) Lewis D O, Pincus J H, Fledman M et al. Psychiatric neurological and psychoeducational characteristics of 15 death row inmates in the US. American journal of psychiatry. 1986; 143: 838-845.

(11) Gallemore J L, Panton I H. Inmate responses to length $\frac{\bar{E}}{\sqrt{2}}$ death row confinement. American journal of psychiatr 1972; 129: 167-172.

(12) American Psychiatric Association. The principles of medical ethics, 1986. 